\title{
Ethical issues and Huntington's disease
}

\author{
J G R Kromberg, BA (Soc Work), MA, PhD; T-M Wessels, MSc
}

Jennifer Kromberg is an Associate Professor in the Division of Human Genetics, Faculty of Health Sciences, University of the Witwatersrand and National Health Laboratory Service (NHLS), Johannesburg, South Africa. Tina-Marie Wessels is Genetic Counsellor Manager, Division of Human Genetics, NHLS and University of the Witwatersrand, Johannesburg, South Africa.

Corresponding author: J G R Kromberg (jennifer.kromberg@nhls.ac.za)

The practice of genetic counselling gives rise to many ethical dilemmas, and counsellors need to be familiar with the principles of biomedical ethics. The primary principles include respect for autonomy, beneficence, non-maleficence and justice. A case of identical twins at $50 \%$ risk for Huntington's disease, in which only one twin sought predictive testing for this dominantly inherited disease, created several ethical dilemmas. Another case where predictive testing was carried out on two young children, at high risk, by a laboratory at the request of an adoption agency and a doctor, with a view to giving information to the foster parents, also posed many ethical conundrums for the counsellor. The ethical issues that arose in these cases are discussed in this paper.

S Afr Med J 2013;103(12 Suppl 1):1023-1026. DOI:10.7196/SAMJ.7146

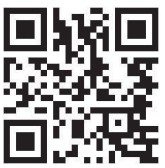

Ethical issues have been of concern to medical geneticists and genetic counsellors in South Africa since the delivery of genetic services officially started in the early 1970s. Ethics, as a form of philosophy, refers to systematic reflection on the moral aspects of life and the associated conflicts that may arise, ${ }^{[6]}$ while biomedical ethics involves the study of ethical issues that occur in research, medicine and society. Traditionally, the paradigm that has guided medical geneticists is principle-based ethics. ${ }^{[7]}$ The primary principles in this system include respect for autonomy, beneficence, nonmaleficence and justice, but autonomy seems to take a central position. ${ }^{[8]}$ The professional may need to balance the demands of competing principles and select a course of action that could sometimes be considered paternalistic and as overriding respect for autonomy. For example, the conditional access to the Huntington's disease (HD) predictive programme $\mathrm{e}^{[5,9]}$ could be seen as paternalistic. The principles are based on the ethics of care, which involve insight into and understanding of someone else's circumstances, needs and feelings, and responsiveness on the part of the counsellor to that person's situation. ${ }^{[10]}$
$\mathrm{HD}$ is a neurodegenerative disease that is inherited as an autosomal dominant condition. ${ }^{[11]}$ The children of an affected parent have a $50 \%$ risk of inheriting the HD mutation and developing the disorder. The symptoms include choreiform movements, progressive dementia, cognitive dysfunction and psychiatric problems; onset is generally in the 40s, although a few juvenile cases have been reported. The causative gene and genetic mechanism were identified in $1993 .{ }^{[11]} \mathrm{HD}$ was found to be a triplet repeat disorder, and affected patients were found to have 40 or more triplet (CAG) repeats, the larger repeat sizes being associated with earlier onset and juvenile cases. With this knowledge, diagnostic, prenatal and predictive genetic testing became possible, and family members at risk could be informed of their status.

In the context of predictive testing for $\mathrm{HD}$, the questions are whether it is ethical to provide individuals with information about their future health when no treatment for the condition is available, what the beneficence, non-maleficence and justice issues are, and if the service is offered, how it should be conducted fairly. ${ }^{[12]}$ To assist genetic counsellors in dealing with these dilemmas, a set of guidelines for HD predictive testing was developed in the 1990s by

Professor Trefor Jenkins has had an interest in medical ethics and its application to genetics for many years. In 1979 he brought an expert in medical ethics, Professor Ernle Young of Stanford University, USA, to South Africa to stimulate interest in ethics and genetics among medical practitioners and students. In 1991 Professor Jenkins published a paper entitled 'Molecular genetics in medicine: Sharing the benefits', ${ }^{[1]}$ in which he discussed the lack of equal access to and uptake of genetic services, the fact that all people in developing countries can benefit from such services, and the need for a more positive attitude to genetic health problems in Africa on the part of medical geneticists and planners.

Subsequently, in 1994, Professor Jenkins was invited to participate in the second worldwide survey on ethics and genetics. This survey included 36 countries, and in South Africa 16 of the possible 21 respondents completed the questionnaire. The local results were reported by Kromberg and Jenkins ${ }^{[2,3]}$ and integrated into the international report by Wertz. ${ }^{[4]}$ In 1996 Professor Peter Harper of the University of Cardiff, Wales, was invited to South Africa and gave a keynote address entitled 'Genetics and society - a challenge for the future'. He covered ethical issues such as the commercialisation of genetic tests, making pre-implantation and prenatal diagnoses, testing of children and confidentiality. From 1998 to 2001 Professor Jenkins was appointed as a part-time lecturer in Medical Ethics at the University of the Witwatersrand, and from 2001 onwards he has been an honorary lecturer in Biomedical Ethics (now the Steve Biko Centre for Bioethics).

In the 1980s the staff of the Divison of Human Genetics set up a predictive testing programme for Huntington's disease. ${ }^{[5]}$ Many ethical issues arose during the genetic counselling involved in offering such testing. It therefore seemed appropriate to examine some of these issues in an article for this Festschrift. 
the International Huntington's Disease Association (IHDA) and the World Federation of Neurology (WFN) and recently revised. ${ }^{[13]}$

In this paper two cases will be described and examined. The ethical principles that were evoked and the dilemmas that arose from these two actual patient consultations, in each of which the counsellor was one of us, will be discussed. The first (counselled by JGRK) involved the problem of possible monozygotic twinning and whether one twin had the right to have predictive testing for HD when the other refused such testing. The second (counselled by TW) presented a dilemma associated with the genetic testing of children, where one parent had HD and the children were being placed into foster care, with the possibility of being put up for adoption.

\section{Predictive testing for $\mathrm{HD}$ in possible monozygotic twins}

Some years ago, one (Twin A) of a pair of apparently monozygotic twin girls (Twins A and B) approached the genetic counselling clinic for a consultation regarding predictive testing for HD. Her mother was affected and had died a few years previously, and the patient, aged 40 years and in a stable relationship, wanted to know her status, as she planned to buy a house. She was aware of her 50\% risk and that molecular testing was available. She added that she had an identical twin (Twin B), living in a distant city, who did not want testing, but their relationship was not close and they seldom communicated.

The predictive testing programme was explained to Twin A and she was told that she would have to see the HD team neurologist, to make sure that she did not have symptoms, and the psychiatrist, to make sure she was stable enough to take the good news (that she did not have the HD mutation) or the bad news (that she did have the mutation), after which she would return to the genetic counsellor for further discussion. Her partner, who accompanied her to this first session, was very supportive, understood the situation and promised further support whatever the result was. Twin A thought that she had a right to be tested, regardless of the reluctance of Twin B. The counsellor recognised that Twin A's autonomy and freedom of choice were being compromised by the attitude of Twin B.

The client consulted the team members, who reported that she was a suitable candidate for testing. The twin sisters had also met, and they agreed that Twin B would consult her own genetic counsellor in the city where she lived. Later, this genetic counsellor confirmed that Twin B was adamant about rejecting testing and that Twin A should therefore be refused testing. This counsellor was concerned about Twin B's rights and the non-maleficence and 'do no harm' principle. As a result, at the next appointment Twin A was told that, since Twin B would not accept testing and a result on Twin A's HD test would give her identical twin an unwanted result, it would not be ethical to test Twin A. (The counsellor was giving precedence to the issues of justice and equality for both twins over the autonomy and rights of Twin A.) Twin A was very upset by this pronouncement, and was determined to return at a later date and demand the test. She stated that she was being controlled by Twin B, was being denied selfdetermination and freedom of choice, and was being discriminated against because she was an identical twin.

At this point, because of the divergent opinions of the two genetic counsellors (each of whom felt that their patient's needs had to be met) and the competing ethical issues in the case, Twin A's counsellor (JGRK) consulted several other genetic counsellors, medical geneticists and medical ethicists on how the case should be managed. Opinions were divided on whether testing should be performed or not and whether Twin A could legitimately be denied the test, and several counsellors were ambivalent.

However, while the twins had said that they were identical, and understood from their mother that they were identical, according to Twin A no DNA testing had ever been performed to confirm zygosity. Research shows that the closest correlation to DNA test results on monozygosity is the twins' own opinion, which was reported to be 95\% correct. ${ }^{[14]}$ When Twin A returned to demand testing, the issue of monozygous twinning and the lack of confirmation that she and Twin B were identical were discussed with her. Since Twin A refused zygosity testing, the counsellor could say that her HD result might not strictly apply to her sister, and that if her sister ever wanted to know her own status, she would have to go through the predictive testing process herself. This solution itself raised ethical issues, but Twin As autonomy and right to be tested was considered to take precedence. The outcome of this session was that the patient had her blood sample sent for analysis. The result showed that she did not have the expansion mutation that causes HD. Subsequently she informed us that Twin B had learned of the result from a family member, but was still refusing to be tested.

\section{Predictive testing in children}

A couple presented at the genetic counselling clinic to discuss the HD test results on the two children placed in their foster care. The foster parents informed the counsellor (TW) that the children's mother had HD and the children (a boy aged 5 and a girl aged 2 at the time) had been removed from her care, but they had little information on the father. The medical practitioner involved was consulted by the adoption agency (which also dealt with foster care) dealing with the case, and HD testing on the children was requested when they were removed from their mother's care. A private laboratory was consulted (possibly because academic laboratories had a policy of refusing to test children unless there were clinical symptoms), performed the tests and gave the results, which showed that one child had the expansion allele and the other did not. A few years after this initial testing the children were placed with the couple in foster care. A paediatrician was then consulted and the children were retested for $\mathrm{HD}$, by the same private laboratory. However, this time the report stated that both children had inherited the condition (each with 50 repeats). Since such results were highly unlikely a sample mix-up could be suspected, and, in addition, these results differed from those of the first test.

During the genetic counselling session these conflicting and unreliable results, and whether testing should be repeated, were discussed with the foster parents (the children were not present). They were also apprised of the pros and cons of testing children and the details of the HD predictive testing guidelines (which recommended protecting children and avoiding testing them unless they had symptoms or treatment was available). The genetic counsellor took the role of child advocate and as such was reluctant to support another request for HD testing. She explained that the autonomy of the children should be respected and their right to choose regarding testing at a later stage preserved. The foster parents were not aware of the early health history of the children, but from their comments there was no convincing evidence of any clinical signs, or of juvenile onset, in either child. Such early onset would have been expected if the children actually had the high number of repeats suggested by the results of the second test. It was then decided that the children should be evaluated by a neurologist, and based on his findings a decision could be made regarding whether or not to repeat the HD testing. 
During follow-up telephonic conversations between the counsellor and the foster mother, she stated that they had not yet pursued the neurology consultation and that the children, now teenagers, were still healthy and would remain in foster care until they were 18 years of age. Although the foster parents felt that their knowledge regarding the children's history of HD was a heavy burden to carry, they had decided not to discuss it with the children. The issues raised by this attitude could not be fully addressed telephonically; however, the foster mother indicated that the foster parents would plan to attend another consultation to discuss the future of the children.

\section{Discussion}

In both these cases the principle of respect for autonomy was in conflict with the rights of the individual. In the first case the right of one twin to know conflicted with the right of the other not to know, and in the second case the rights of the children to their own genetic knowledge and to give informed consent to testing conflicted with the rights of the adoption agency and the foster parents to full information. In both cases paternalistic decisions were made initially, which were not satisfactory, did not take into account all the ethical issues, and had to be altered later.

Many ethical issues arose in these cases. Certainly issues of respect for autonomy, beneficence, non-maleficence and justice (inequality), and even issues of paternalism, were faced. In the first case the autonomy of Twin A clashed with that of Twin B. Individualistic paradigms and traditional bioethical frameworks support the presenting autonomous individual as the primary clinical unit. ${ }^{[15]}$ This approach prioritises her/his right to know over another's right not to know, even when the other at-risk person has her/his own legitimate claim. Autonomy and the absence of coercion are prerequisites for the testing individual, but when accepted they apply coercion on the other party, who loses her autonomy and the right to have her opinion accommodated at the same time. In a comparable situation, current clinical practice would prioritise the right of an adult offspring to be tested over the right of an at-risk father not to be tested, and this approach has been supported by the IHDA and the WFN ${ }^{[16]}$ However, the 2013 guidelines state that 'extreme care should be exercised when testing would provide information about another person who has not requested the test. ${ }^{\left[{ }^{[13]}\right.}$ These dilemmas have to be faced by genetic counsellors and clinicians who administer genetic services. ${ }^{[15]}$

Comparative justice was also highlighted when the needs of one individual had to be weighed against those of another (in this case Twin A and Twin B), taking into consideration the possible consequences for the twins themselves, and the need to try to identify who would benefit more and who would be harmed more. The duty of the counsellor to warn a third party also came up in this case (i.e. the impact of the client's genetic information on the at-risk relative is indeed serious when that relative is an identical twin), although this duty to prevent harm conflicted with the duty to preserve confidentiality.

Although the issue of monozygotic twins is not specifically mentioned in the guidelines for testing, ${ }^{[13]}$ the problems associated with predictive testing in twins have been recognised and, because the result in one would automatically confirm the result in the other, it has been suggested that testing is unwise. ${ }^{[17]}$ However, a case where molecular testing occurred has been described. In this case the twins, although one twin initially stated that they were dizygotic, were tested and found to be monozygotic prior to HD predictive testing. ${ }^{[18]}$ They then both agreed to have testing; this was co-ordinated by two counsellors, as the twins lived in different cities, and simultaneous provision of results was arranged. In the present case, the fact that zygosity was not confirmed allowed the counsellors to adhere to both twins' rights to autonomy and individuality, as well as to the principle of non-maleficence, by causing the least harm to both.

In the second case predictive testing of children was performed, although it was of no direct benefit to them. Here the predictive testing guidelines are clear on recommending that testing should not be performed to determine the suitability of a child for adoption (or, in the present case, foster care) ${ }^{[13,1,19]}$ Information on the status of children could lead to discrimination, stigmatisation and insult to the psychological wellbeing of the child. ${ }^{[20-22]}$ Such testing raises questions regarding intrafamilial relationships, confidentiality, disclosure and paternalism. The benefits (generally relating only to the parents, but in the present case also to the adoption society staff, on behalf of the foster parents) include removing parents worries, facilitating planning and preparing for the future, taking advantage of available technology, providing early treatment (where the disorder is treatable, e.g. phenylketonuria), and maintaining vigilance in healthcare. However, the harms (generally relating to the child) include disturbing the parent-child relationship, damaging the child's self-esteem, raising anxiety about the onset of symptoms, removal of the child's right to decide, and providing no direct benefit to the child (e.g. in HD). In many cases, parents consider it their right to decide, on behalf of the child, whether and when to have testing undertaken. In the present case the adoption society, who were involved in placing the children, made the testing decision, so that the foster parents could be fully informed about the health of the children to be fostered and could make their decisions accordingly. Whether the society was in fact obliged to inform the prospective foster parents about this history is debatable. However, if the agency had informed the foster parents of the family history only, the autonomy of the children could have been maintained. Children may therefore need a child advocate (a genetic counsellor can play this role) to protect their interests.

Early in the 1990s the British Society of Human Genetics stated that there should be a general presumption against genetic testing when there is no health benefit for the child. ${ }^{[23]}$ Many guidelines support the child's right to autonomy in making decisions at the age of 18 years ${ }^{[24]}$ however, an informed decision should be made, and the age at which this is possible is usually considered to be 18 years. ${ }^{[3]}$ Although the children in the present case were younger than 18 years, and although the foster parents were reluctant to discuss the HD history with them, they should be informed of their at-risk status according to current recommendations ${ }^{[13]}$ Professionals should assist the parent, or in this case the adoption agency and foster parents, to consider how to inform the children and to arrive at a decision that results in least harm. ${ }^{[25]}$ The foster parents should have had 'access to genetic counseling, support and information including discussion of all their options for dealing with [their foster children] being at risk. ${ }^{[13]}$ However, a study by Duncan et al.${ }^{[21]}$ found that in the case of 22 immature minors who were tested for HD, testing was mostly requested by the parents and in $64 \%$ the results were not communicated to the children. Studies on the attitudes of parents and children in this situation have been reviewed by Michie and Marteau, ${ }^{[26]}$ who highlighted the need for increasing relevant psychological research.

A further ethical issue to consider is the role of the genetics laboratory in testing children. According to the recent guidelines for predictive genetic testing, the laboratory should ensure that 
such testing is accompanied by genetic counselling. ${ }^{[13]}$ Although the term genetic counselling has not been defined in these guidelines, it is unlikely that either the adoption agency staff or the medical practitioners involved had the necessary skills to provide such counselling. The laboratory staff should therefore not be absolved from their responsibility, in the present case and in future similar cases, to test only in the context of appropriate counselling.

\section{Conclusion}

The cases described here illustrate the difficulties that arise in dealing with ethical issues in practice. Experience and ethical guidelines are often helpful in resolving dilemmas, but genetic counsellors may arrive at different solutions in similar cases, or no solution may be found.

How then should ethical issues be resolved? A code of ethics has been drawn up for medical geneticists ${ }^{[27]}$ and for genetic counsellors (this code is promoted by the National Society of Genetic Counselors in the USA, and published in Appendix A in Veach et al. $\left.{ }^{[28]}\right)$. Also, in these situations there are a few general guidelines for what genetic counsellors (having become familiar with the basic principles of bioethical practice) should do, and the use of the ETHIC model is suggested: Examine relevant personal, societal, client and professional values; Think about what ethical standard of the code of ethics applies to the situation, as well as about relevant laws and case discussions; Hypothesise about the possible consequences of different decisions; Identify who will benefit and who will be harmed; and Consult with supervisors and colleagues about the most ethical choice. ${ }^{[29]}$

Although the Health Professions Council of South Africa has its own code of ethics for guiding professional behaviour, South Africa still requires ethical guidelines for genetic services, and these need to be developed by the Department of Health in consultation with the South African Society of Human Genetics, the professionals providing services in the field, and consumers of the service. Because access to genetic information is expanding exponentially, it is important to be aware of the ethical issues involved in providing this information to the public, and the present study gives some indication of how complex these issues can be. Resolving ethical dilemmas is challenging, each situation is unique, often there are no ethically right or wrong answers, and often a contextual clinical judgement must be made. ${ }^{[25]}$

Acknowledgement. JGRK acknowledges the Mellon Mentorship scheme for funding support.

\section{References}

1. Jenkins T. Molecular genetics in medicine: Sharing the benefits. In: Roberts DF, ed. Molecular Genetics in Medicine: Advances, Applications, and Ethical Implications. London: Macmillan, 1991:161-183.

2. Kromberg J, Jenkins T. Cultural influences on the perception of genetic disorders in the black population of southern Africa. In: Clarke A, Parsons E, eds. Culture, Kinship and Genes. London: Macmillan, 1997:147-157.

3. Kromberg J, Jenkins T. Ethical, legal, and sociocultural issues and genetic services in South Africa. In: Kumar D, ed. Genomics and Health in the Developing World. Oxford: Oxford University Press, 2012:585-598.

4. Wertz DC. Patients' and professionals' views on autonomy, disability, and 'discrimination'. In: Caulfield TA, Williams-Jones B, eds. The Commercialization of Genetic Research: Ethical, Legal and Policy TA, Williams-Jones B, eds. The Commercialization of Gen
Issues. New York: Kluwer Academic/Plenum, 1999:171-180.

5. Kromberg J, Krause A, Spurdle AB, et al. Utilisation of predictive, prenatal and diagnostic testing for Kromberg J, Krause A, Spurdle AB, et al. Utilisation of predictive, prent
Huntington's disease in Johannesburg. S Afr Med J 1999;89(7):774-778.

6. Wertz DC, Fletcher JC, Berg K. Review of Ethical Issues in Medical Genetics. Geneva: World Health Organisation, 2003

7. McConkie-Rosell A, Spiridigliozzi GA. 'Family matters': A conceptual framework for genetic testing in children. J Genet Couns 2004;13(1):9-29. [http://dx.doi.org/10.1023/B:JOGC.0000013379.90587.ef]

8. Huibers AK, van't Spijker A. The autonomy paradox: Predictive genetic testing and autonomy: Three essential problems. Patient Educ Couns 1998;35(1):53-62. [http://dx.doi.org/10.1016/S07383991(98)00083-4]

9. Sizer EB, Haw T, Wessels T-M, Kromberg JGR, Krause A. The utilization and outcome of diagnostic, predictive, and prenatal genetic testing for Huntington disease in Johannesburg, South Africa. Genet Test Mol Biomarkers 2012;16(1):58-62. [http://dx.doi.org/10.1089/gtmb.2011.0007]

10. Schmerler S. Ethical and legal issues. In: Baker DL, Schuette JL, Uhlmann WR, eds. A Guide to Genetic Counseling. New York: Wiley-Liss, 1998:249-275.

11. Bates G, Harper PS, Jones P. Huntington's Disease. 3rd ed. Oxford: Oxford University Press, 2002.

12. Terrenoire G. Huntington's disease and the ethics of genetic prediction. J Med Ethics 1992;18(2):79-85. Terrenoire G. Huntington's disease and the
[http://dx.doi.org/10.1136/jme.18.2.79]

13. MacLeod R, Tibben A, Frontali M, et al. Recommendations for the predictive genetic test in Huntington's disease. Clin Genet 2013;83(3):221-231. [http://dx.doi.org/10.1111/j.1399-0004.2012.01900.x]

14. Ohm Kyvik K, Derom C. Data collection on multiple births - establishing twin registers and determining zygosity. Early Hum Dev 2006;82(6):357-363. [http://dx.doi.org/10.1016/j.earlhumdev.2006.03.013]

5. Taylor SD. Predictive genetic test decisions for Huntington's disease: Context, appraisal and new moral imperatives. Soc Sci Med 2004;58(1):137-149. [http://dx.doi.org/10.1016/S0277-9536(03)00155-2]

16. See I. Guidelines for the molecular genetics predictive test in Huntington's disease. Neurology 1994;44:1533-1536.

17. Harper PS. Genetic aspects of Huntington's disease. In: Harper PS, ed. Huntington's Disease. London: Saunders, 1991:281-315

18. Heimler A, Zanko A. Huntington disease: A case study describing the complexities and nuances of predictive testing of monozygotic twins. J Genet Couns 1995;4(2):125-137. [http://dx.doi.org/10.1007/ BF01408635]

19. Bombard Y, Semaka A, Hayden M. Adoption and the communication of genetic risk: Experiences in Huntington disease. Clin Genet 2012;81(1):64-69. [http://dx.doi.org/10.1111/j.1399-0004.2010.01614.x]

Huntington disease. Clin Genet 2012;81(1):64-69. [http://dx.doi.org/10.1111/j.1399-0004.2010.01614.x]
20. Malpas PJ. Predictive genetic testing of children for adult-onset diseases and psychological harm. J Malpas PJ. Predictive genetic testing of children for adult-onset diseases and
Med Ethics 2008;34(4):275-278. [http://dx.doi.org/10.1136/jme.2006.019802]

21. Duncan RE, Savulescu J, Gillam L, Williamson R, Delatycki MB. An international survey of predictive genetic testing in children for adult onset conditions. Genet Med 2005;7(6):390-396. [http://dx.doi. org/10.1097/01.GIM.0000170775.39092.44]

22. Duncan RE. Predictive genetic testing in young people: When is it appropriate? J Paediatr Child Health 2004;40(11):593-595. [http://dx.doi.org/10.1111/j.1440-1754.2004.00481.x]

23. Went $\mathrm{L}$. Ethical issues policy statement on Huntington's disease molecular genetics predictive test. International Huntington Association. World Federation of Neurology. J Med Genet 1990;27(1):34-38. [http://dx.doi.org/10.1136/jmg.27.1.34]

24. Richards FH, Tassicker RJ, Kromberg JGR, Singaram BM. Predictive genetic testing in children. Med J Aust 2002;176(10):507.

25. Lucassen A, Fenwick A. Testing children for adult onset conditions: The importance of contextual clinical judgement. J Med Ethics 2012;38(9):531-532. [http://dx.doi.org/10.1136/ medethics-2012-100678

26. Michie S, Marteau TM. Predictive genetic testing in children: The need for psychological research. British Journal of Health Psychology 1996;1(1):3-14. [http://dx.doi.org/10.1111/j.2044-8287.1996.tb00487.x]
J 1 .

27. Wernal of Health Psychology 1996; (1):3-14. [http:///dx.doi.org/10.1111/j.2044-8287.1996.tb00487.x]
DC, Fletcher JC. Proposed: An international code of ethics for medical genetics. Clin Genet 2008;44(1):37-43. [http://dx.doi.org/10.1111/j.1399-0004.1993.tb03839.x]

28. Veach PM, LeRoy B, Bartels DM. Facilitating the Genetic Counseling Process: A Practice Manual. New York: Springer, 2003.

29. Congress EP. What social workers should know about ethics: Understanding and resolving practice dilemmas. Advances in Social Work 2000;1(1):1-22.

Accepted 12 August 2013. 